Products and Services In Practice is provided to readers using text and images from the manufacturer, supplier or distributor and does not imply endorsement by $B D J$ In Practice. Normal and prudent research should be exercised before purchase or use of any product mentioned.

Please send product and services news through to David Westgarth, BDJ In Practice via: bdjinpractice@bda.org

\section{Quality every time}

Have your patients always wanted to enjoy a professionally cleaned feeling every day? Then look no further, because Curaprox have the product for them.

The Hydrosonic Pro sonic toothbrush can deliver this after every use. This toothbrush is suitable for everyone whether they have braces, implants, or sensitive gums they can use the Hydrosonic Pro and still experience a professional quality clean every time. CURACURVE bend enables the brush head to clean hard to reach areas especially as implants and braces can make good oral hygiene more challenging.

CUREN bristles are designed to provide the best possible performance, working alongside ultrasound technology to clean on two levels: mechanically and hydrodynamically. This leaves your patients with a clean that a manual toothbrush could only dream of providing.

For more information call 01480 862084, email info@curaprox.co.uk or visit www.curaprox.co.uk.

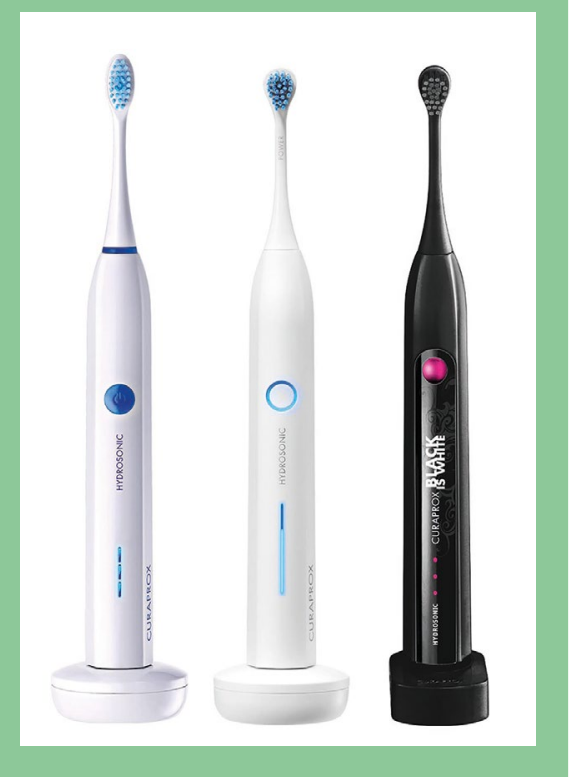

\section{A simple solution to your air supply}

Looking after your air supply shouldn't be complicated.

That's why DENTALAIR UTILITIES aims to revolutionise your air supply with Air to the Chair.

Air to the Chair is easy, all you need to do is log onto the website and select the

'New Air Supply' option from the top of the screen.

Following this, indicate how many chairs you need an air supply for and you will instantly be given a fixed subscription price. This includes a brand new air supply, written documentation to assist with inspections, regular maintenance and complete breakdown cover.

There are no credit checks necessary and DENTALAIR UTILITIES always works around your schedule to provide an exceptional level of customer service!
To find out more contact DENTALAIR UTILITIES at info@dentalair.com or call 08009757530 .

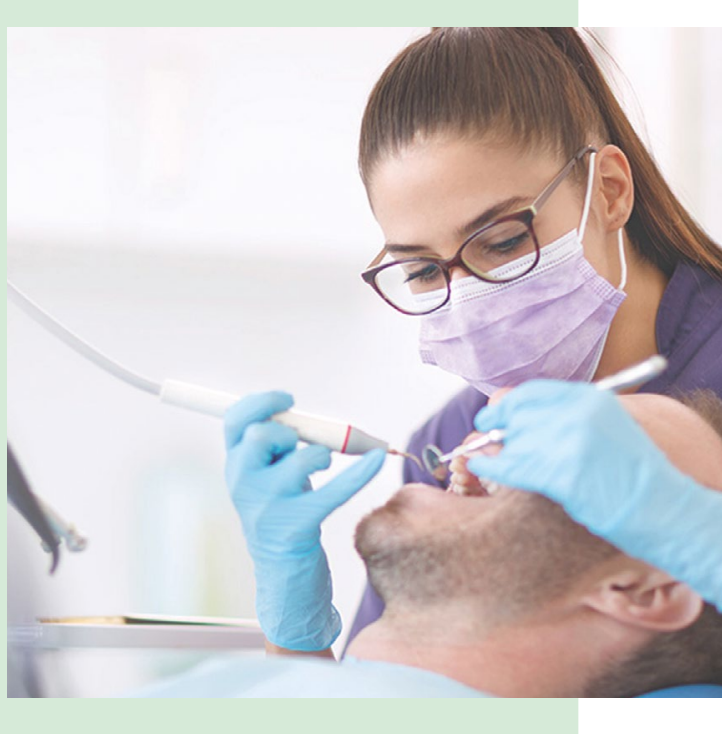

\section{Accredited dental implant education, for your best career}

For accredited postgraduate training in implant dentistry, The One to One Implant Education's Postgraduate

Diploma in Implant Dentistry is the only choice.

Under the guidance of Course Lead and renowned implant dentist, Dr Fazeela Khan-Osborne, and with substantial portion of the teaching time dedicated to live surgery, the programme has a tiered peer mentor system, with every delegate receiving a tutor who has also completed the course.

Training covers:

$\rightarrow$ Treatment planning

$\rightarrow$ Soft tissue management

$\rightarrow$ The laboratory/clinician interface

$\rightarrow$ Guided bone regeneration and more.
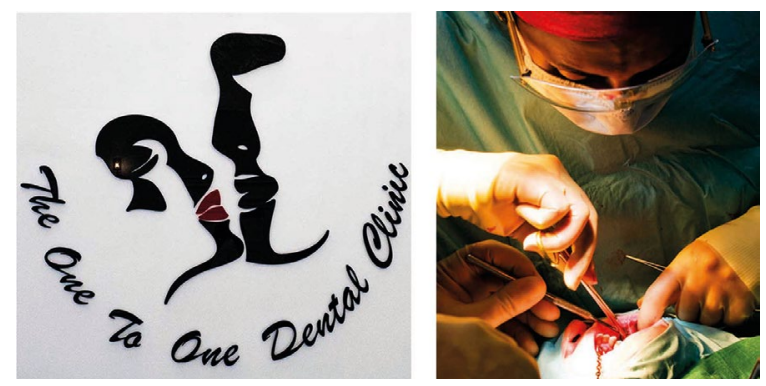

With the 2021

Postgraduate Diploma sold out, book for 2022 to avoid disappointment!

To reserve your place or to find out more, visit https://121implanteducation. co.uk or call 02074860000 . 